NOTICE: this is the author's version of a work that was accepted for publication in Journal of Pediatrics. Changes resulting from the publishing process, such as peer review, editing, corrections, structural formatting, and other quality control mechanisms may not be reflected in this document. Changes may have been made to this work since it was submitted for publication. A definitive version was subsequently published in Journal of Pediatrics, Vol. 162, no. 3 (2013). DOI: 10.1016/j.jpeds.2012.09.007 


\section{Maternal life stress events in pregnancy link to children's school achievement at age 10}

Jianghong Li, $\mathrm{PhD}^{1,2}$, Monique Robinson, $\mathrm{PhD}^{2}$, Eva Malacova, $\mathrm{PhD}^{3}$, Peter Jacoby, $\mathrm{MSc}^{2}$, Jonathan Foster, $\mathrm{PhD}^{4}$, and Anke van Eekelen, $\mathrm{PhD}^{2}$

1. Curtin Health Innovation Research Institute, Centre for Population Health Research, Curtin University, Telethon Institute for Child Health Research, Perth, Australia

2. Telethon Institute for Child Health Research and Centre for Child Health Research at The University of Western Australia, Perth, Australia

3. Curtin Health Innovation Research Institute, The National Drug Research Institute, Curtin University, Perth, Australia

4. Curtin Health Innovation Research Institute, School of Psychology and Speech Therapy, Curtin University, Perth, Australia \& Neurosciences Unit, Health Department of WA

Corresponding author: Dr Jianghong Li, PO Box 855, West Perth, WA 6872, Australia; Tel: +618 9489 7800; Fax: +61 89489 7700; Email: jianghong1@ichr.uwa.edu.au.

Key words: life stress events, pregnancy, maternal, numeracy, literacy, Raine Study

Funding: The Western Australian Pregnancy Cohort (Raine) Study is funded by the National Health and Medical Research Council (NH\&MRC) of Australia, the Telethon Institute for Child Health Research, the University of Western Australia (UWA), the Raine Medical Research Foundation, the UWA Faculty of Medicine, Dentistry and Health Sciences, Australian Health Management and the Women and Infants Research Foundation. Dr Robinson is funded by Australian Rotary Health.

\section{Conflict of Interests}

All authors declare that there are no conflicts of interest to disclose. The founders of the Raine Study had no involvement in the study design, the collection, analysis and interpretation of data, neither in the writing and the decision to submit the paper for publication.

Jianghong Li wrote the first draft of the manuscript and all co-authors contributed to various drafts. No honorarium, grant or any other form of payment was given to any authors to produce the final version of the manuscript.

\section{Acknowledgements}

We gratefully acknowledge the Raine Study participants and their families for their participation in the Study and the Raine Study Team for cohort co-ordination and data collection. 


\begin{abstract}
OBJECTIVE: Limited research has examined maternal exposure to common life stress events (LSEs) in pregnancy and academic achievement in children. We hypothesized that maternal antenatal exposure to LSEs was associated with lower achievement in literacy and numeracy at age 10, with sex differences in this link.
\end{abstract}

METHODS: The Western Australian Pregnancy Cohort Study recruited 2900 women at 18 weeks' pregnancy and 2868 children were followed up at birth and postnatally. At age 10, information on 1038 children was linked to their literacy and numeracy test scores. Multivariate regression models were used to test the above hypotheses, adjusting for important confounders.

RESULTS: In girls, antenatal exposure to four or more LSEs, or death of a friend and/or relative was associated with lower reading scores. In contrast, exposure to three or more LSEs or to pregnancy problem or financial problems was associated with higher reading scores in boys. Further, maternal exposure to four or more LSEs was associated with higher mathematic scores, and residential move was linked to higher scores in writing in boys.

CONCLUSIONS: Maternal antenatal exposure to LSEs has a differing effect on female and male offspring's school performance. Further research is needed to explore the reasons for the sex difference. 


\section{INTRODUCTION}

A substantial body of evidence has linked maternal stress in pregnancy to difficult infant temperament [1-3], child behavioural problems [4-9] and Attention Deficit Hyperactivity Disorder (ADHD) symptoms in children between four and 15 years of age $[4,10]$. Other studies have also shown a negative effect of maternal stress in pregnancy on cognitive development $[1,3,11,12]$.

Previous research linking maternal stress in pregnancy to child cognitive development are mainly based on small study samples ( $<100$ participants) and focused on infants, toddlers or young children. However, middle childhood and adolescence are important developmental stages at which individual cognitive capabilities become more differentiated and stabilised [7]. It is also at this developmental stage that self-regulatory capacities (executive functions) begin to develop and mature throughout the teenage years $[13,14]$. Indeed, a few studies have linked maternal stress in utero to cognitive functions in middle childhood and adolescence $[4,15,16]$.

Children's numeracy and literacy achievement is an important outcome measure of cognitive development, with significance for an individual's capability to participate successfully in society later in life. The consequences of low educational achievement include low self-esteem, social, emotional and behavioural problems, early drop out from school, unemployment, and ultimately poverty [17], with a risk of an inter-generational transmission of disadvantage $[18,19]$. Only one study has examined the link between maternal stress events in pregnancy and academic performance [20]. Niederhofer and Reiter [21] examined the association between the occurrence of any of 26 self-reported maternal stress events between 16 and 20 weeks of gestation in 227 women in Vienna (Austria) and fetal movement (measured by ultrasound imaging), followed by evaluation of child temperament at six months of age and teacher-reported marks in literacy, numeracy and music at age six. The findings revealed that maternal antenatal stress events related to 
socioeconomic issues (e.g. financial problems) and psychological factors (e.g. isolation) were associated with lower marks in all these three subjects.

A range of animal studies has demonstrated sex differences in the effect of maternal psychological stress in pregnancy on behavioural and cognitive outcomes in offspring (see [22] for a review). Previous research on humans suggests that female fetus is more sensitive to changes in placental cortisol concentrations resulting in alterations in growth [23]. Female children and adolescents affected by Hurricane Katrina in the US in 2005, reported higher levels of depressive symptoms and post-traumatic stress disorder than their male counterparts $[24,25]$. These gender differences may be attributed to genetic variability within the stress regulatory systems [26,27], which suggest that there may be gender differences in the effect of maternal exposure to LSEs in pregnancy on offspring's numeracy and literacy skills.

The present study examined the relationship between maternal exposure to common life stress events (LSEs) in pregnancy and achievement in numeracy, reading, spelling and writing among children in the relatively large Western Australian Pregnancy Cohort (Raine) Study who had reached age 10 and attended grade five of the Australian primary school system. We hypothesized that 1) maternal exposure to LSEs in pregnancy was negatively associated with academic achievement at age 10, independent of maternal social and demographic characteristics, maternal smoking in pregnancy, family income, and life stress events at age 10;2) Maternal exposure to LSEs in pregnancy would affect boys and girls differently in their academic achievement at age 10.

\section{METHODS}

\section{Study Population}

The study was based on longitudinal data from the Raine Study, a prospective cohort study of 2,868 live births, with ongoing follow-ups. The Raine Study recruited 2,900 pregnant women between 
1989 and 1991 through the state maternity hospital, King Edward Memorial Hospital (KEMH), and nearby private clinics in Perth, Western Australia (WA). These women were recruited between 16 and 20 weeks gestation, with sufficient English language skills and an intention to deliver their baby at $\mathrm{KEMH}$ and to reside in WA so that their child could be followed up [28].

Participants provided data regarding their pregnancy, maternal physical health, maternal experience of common life stress events (LSEs), and psychosocial and demographic characteristics at enrolment and at 34 weeks of gestation. The primary carer (mostly mother) and the child were followed up at birth, and at ages one, two, three, five, eight, 10, 14 and 17 years. The primary caregiver provided informed consent at enrolment and at each subsequent follow-up after birth. The study was approved by the Human Research Ethics Committees at KEMH and Princess Margaret Hospital for Children in Perth.

The present study was based on a subset of the Raine Cohort at age 10. These children $(\mathrm{N}=1038$ : 521 boys and 516 girls) were attending government schools in grade five and were linked to the data from the Western Australian Literacy and Numeracy Assessment (WALNA) conducted by the Western Australian Department of Education and Training. These children represent about $51 \%$ of the cohort that was followed up at age $10(\mathrm{~N}=2047)$. Compared to the children who were followed up at age 10 but not linked to WALNA, the subset were less likely to be born to teenage mothers $(\mathrm{p}<0.001)$ or mothers who were never married $(\mathrm{p}=0.05)$, or to families with an annual income below \$AUD36,000 in 1989-199 ( $\mathrm{p}=0.02)$, with absolute differences of around 4 percentage points. There was no difference in maternal education $(\mathrm{p}=0.70)$. Children who attended non-government schools were not included in this data linkage because additional permission and consent from the Independent Schools' Association could not be obtained at the time. The WALNA and Raine data were linked by the West Australian Data Linkage System using a probabilistic method of matching based on full names, date of birth, sex and address as described elsewhere [29]. 


\section{Numeracy and Literacy assessment at age 10}

A standardised score was derived from a raw test score for mathematics, reading, writing and spelling, administered through the WALNA program. The WALNA was administered annually to all students in WA in grades three, five, and seven. The WALNA is directly comparable to other Australian state wide assessment programs of children's school achievement, and it was evaluated annually for content and construct validity by psychometricians.

The raw scores were standardised based on a historical scale developed by the WA Department of Education and Training to enable comparisons over time (Appendix 2). These scores were converted from an ordinal scale into an interval scale via a Rasch measurement model [30] to enable easier interpretation and to allow for monitoring of children's progress in literacy and numeracy skills over time. The interval scale measures the level of achievement in mathematics, reading, writing and spelling, with a higher score indicating a higher level of achievement.

\section{Stress events in pregnancy}

The pregnant mothers completed a questionnaire at 18 and 34 weeks' gestation, which included the question of whether or not they experienced any of 10 life stress events (LSEs). The 10 LSEs included pregnancy problems, the death of a close friend or relative, separation or divorce, marital problems, problems with other children in the family, own job loss (involuntary), partner's job loss (involuntary), financial problems, residential move and other stressful events. At 18 weeks' gestation mothers were asked whether they had experienced any of these LSEs since she became pregnant, while at 34 weeks' gestation mothers were asked whether any of these stressful events occurred since 18 weeks' gestation. Possible answers to these questions were dichotomous ("yes"/"no") to reduce recall difficulties and bias [31].

We adopted the scale developed by Miller and Rahe [32] to weight the 11 stress events according to severity, with the death of a relative having the largest weight (96) and residential move the lowest 
score (41). The total weighted score counts all life stress events experienced at both 18 and 34 weeks of pregnancy. If a mother reported a total of three different life stress events (e.g., death of a close relative, separation or divorce, residential move) at both time periods, her total weighted score is equal to $92+79+41=212$ and the weighted average score for her pregnancy is 212 / 2 (time periods $)=106$, which was used in the analysis. In addition, we examined the following three aspects of exposures to LSEs in pregnancy to provide a more nuanced view of the effect of antenatal stress exposure on learning outcomes.

The frequency of LSE: A total LSEs index score was derived by summing the number of "yes" responses to any of the 10 life stress events throughout the pregnancy, giving equal weight to each and excluding the missing cases $(7 \%, \mathrm{n}=74)$. Preliminary analysis suggested that the number of the LSEs had a nonlinear association with the outcome variables and hence we collapsed the total number of LSEs into: no LSE, one or two LSEs, three LSEs, and four or more LSEs. The timing of LSE: Four categories were examined: No stress events in pregnancy (reference group), LSEs in early pregnancy only (up to 18 weeks' gestation), LSEs in mid-pregnancy only (between 19-34 weeks' gestation), and LSEs since pregnancy up to 34 weeks' gestation. The type of LSE: We examined whether the mother had experienced each of the 10 LSEs ("yes"/"no") at any time during pregnancy.

\section{Confounding Variables}

Many of the LSEs under investigation are closely associated with or caused by social and economic disadvantage, such as marital problems, involuntary job loss, money problems, and residential mobility [33]. To control for these possible confounders, we included in multivariate analyses maternal age $(<20,20-24,25-29,30-34$, and 35 or older), mother's education (no schooling, trade certificate/other qualification type/college diploma, professional degree and university degree), mother's marital status (married, never married/defacto, separated/divorced or widowed), maternal race (Aboriginal, Caucasian, other), family income (less than \$AUD24,000, 24,000-35,999, 36,000 or more), and the average number of cigarettes mothers smoked daily at 18 weeks of gestation $(0,1$ - 
5 , 6-10 , 11-15, 16-20 , 21 or more). Further, as several of maternal LSEs in pregnancy could persist in infancy and age 10 when the child took the literacy and numeracy tests, the LSEs at these two later developmental stages were a plausible confounder. To adjust for this factor, we have also included in all multivariate analyses a weighted scale of stress events at ages one and 10, using the same weighting scale for the LSEs reported in pregnancy.

\section{Analysis}

We tested for main effects and sex interactions with each measure of maternal exposure to LSEs, with adjustment for the confounders. Analyses were accomplished using multivariate general linear regression models in SPSS version 16. The sex interactions were tested by including interaction terms (e.g., sex*weighted_stress) along with other covariates and a request for marginal means in the model statement. The term "effect" is used in a statistical context and was interchanged with the term "association", without the intention to claim full causality. An effect of $p \leq 0.05$ was considered as statistically significant, with due attention to overall patterns and the magnitude of the effect where the $\mathrm{p}$ value is $\leq 0.10$.

\section{Results}

Boys had a higher average score for mathematics but lower scores for all three measures of literacy (Table 1). There were considerable sex differences in the average scores of reading $(\mathrm{p}=0.049)$, spelling $(\mathrm{p}=0.01)$, writing $(\mathrm{p}=<0.001)$ and numeracy $(\mathrm{p}=0.069)$. The standard deviation in numeracy outcomes was larger in boys than in girls, but the opposite held true for spelling and writing.

On average, the mothers of the Raine Study Cohort subset experienced two stress events in pregnancy (Table 2). Nearly $80 \%$ of them experienced at least one stress event sometime during pregnancy, and in $42.7 \%$ of the mothers a LSE occurred at both 18 and 34 weeks of gestation. The most commonly reported LSEs were pregnancy problems (37.4\%), followed by money problems (35.5\%), residential move (25.4\%), other problems (21.5\%), and marital problems (11.9\%). On the 
weighted scale, the mean score of total stress exposure is 59.7, with a minimum of 0 and a maximum of 352 .

\section{Reading}

Weighted scale of total stress exposure: overall maternal LSEs in pregnancy have a negative effect on daughters' reading test scores but a positive effect for sons independent of the potential confounders (Table 3): for one unit increase in the stress scale, the reading score decreased by .18 points in girls but it increased by .17 points in boys. The sex difference is statistically significant $(b=-0.27, p=0.023 .95 \% C I:-0.50,-0.04)$. When a weighted stress scale for the LSEs at age one was added to the multivariate models, the negative effect in girls decreased only somewhat (from beta $=.18$ to beta $=.17$ ) even though the statistical significance was reduced from $\mathrm{p}=0.04$ to $\mathrm{p}=0.08$. For boys, the positive effect on reading increased from beta $=.17$ to .21 and $p$ value from 0.05 to 0.02 .

Frequency of antenatal LSEs: Girls whose mother experienced four or more LSEs scored about 33 points lower in their reading test, compared to the reference group (no stress events) (Table 3). In contrast for boys, maternal exposure to three or more LSEs was associated with an increase of about 41 points in the reading test score. The sex interaction with the frequency of exposure to LSEs was statistically significant $(\mathrm{p}=0.02, \mathrm{~F}=3.12, \mathrm{df}=3)$, adjusting for maternal age, race, marital status, education, smoking in pregnancy, family income, and a weighted stress scale at ages one and 10 (Figure 1). The mean reading score for girls did not differ between "no stress events" and "1-2 stress events" (about 401 vs 402) but it decreased slightly at "3 stress events" (400), and more substantially when mothers were exposed to four or more stress events (372). However, in boys the score started to increase by about 20 points from 366 to 386 with "1-2 stress events", and it further increased to 400 points with three events, before decreasing somewhat to about 396 points with maternal exposure to four or more LSEs. 
Timing of the exposure: Boys whose mothers experienced LSEs at any time up to 34 weeks of gestation had a higher average reading score by about 33 points, compared to no stress exposure (Table 3), but the timing of the exposure had no significant effect on girls.

Specific LSEs: In girls whose mothers experienced the death of a friend or a relative in pregnancy the mean reading score was reduced by 97 and 35 points, respectively. However, exposure to pregnancy and money problems was associated with higher reading scores in boys (by 21 and 27 points, respectively).

\section{Spelling, writing and mathematics}

Further multivariate analyses (not shown) with adjustment of the potential confounders showed that neither the timing nor the type of LSEs in pregnancy was associated with spelling, writing or mathematics in girls. In boys, maternal exposure to three LSEs in pregnancy was associated with an increase of 36 points ( $\mathrm{p}=0.03,95 \%$ CI: $4.32,67.40)$ and four or more LSEs was associated with 42 points ( $\mathrm{p}=0.01,95 \% \mathrm{CI}: 10.19,72.19)$ in numeracy score; exposure to residential move was associated with a higher mean score for writing (42 points, $\mathrm{p}<0.02,95 \% \mathrm{CI}$ : $-11.97,72.74$ ).

\section{Discussion}

Maternal exposure to four or more stressful life events in pregnancy was associated with lower reading score in grade five girls. Specifically, the death of a relative and/or the death of a friend in pregnancy was linked to lower reading achievement in girls, independent of maternal sociodemographic characteristics, family income, maternal smoking in pregnancy and common life stress events in infancy and middle childhood. No specific timing of antenatal exposure to LSEs was linked to school achievement in either girls or boys at age 10. When antenatal exposure to LSEs was analysed as a single weighted scale, the overall findings remained largely unchanged, with one caveat: the negative effect of LSEs in pregnancy on reading decreased somewhat, suggesting that the effect may be to some extent attributed to the LSEs at age one, also a critical period for brain development [34]. 
Overall, our findings in girls corroborate limited previous research that has linked maternal stress in pregnancy to reduced marks in reading and mathematics at age six (grade 1) [20]. However, unlike Niederhofer and Reiter's study [21], our measures of academic achievement were derived from the scores of a standard state wide test at age 10, whereas the previous study was based on teacherreported academic marks at age six.

\section{Mechanisms}

Van den Bergh and co-authors have proposed a fetal programming hypothesis [35], whereby a mother's exposure to stress or anxiety in pregnancy will raise her cortisol level, which in turn crosses the placenta to affect the fetus and disturb ongoing fetal growth and development [36]. This hypothesis implies that maternal antenatal stress can affect fetal brain development, including the stress-regulatory HPA-axis, limbic system and prefrontal cortex of the child. If maternal stress disrupts fetal brain development, it can have long-term consequences for cognitive development after birth. Whether excess glucocorticoid exposure is the only biological mechanism that links maternal stress in pregnancy to offspring's cognitive and academic performance remains uncertain. Vascular compromise of the placenta and undernutrition of the developing fetus due to maternal stress exposure are also known to shape fetal programming. However, these biological events seem to be associated more with systemic disease development during the course of life [36]. To better understand the biology underpinning developmental programming, future studies will need to collect information about such biological indicators in pregnant mothers exposed to LSEs.

One of the most consistent findings of previous studies on maternal stress in pregnancy and neurobehavioral development is an increased risk for Attention Deficit Hyperactivity Disorder in children [7]. Research has also linked maternal prenatal psychosocial stress to poor working memory in female offspring when they reach young adulthood $[35,37]$. It is plausible that maternal antenatal exposure to LSEs leads to poor attention span in children, which in turn may negatively 
affect reading comprehension. However, it is not clear on the basis of this account why discordant findings have been obtained in boys versus girls in our current study.

\section{Sex differences}

In contrast to the negative effect of maternal exposure to multiple LSEs in pregnancy on reading achievement among the girls of our study population, we found that boys whose mothers experienced three or more LSEs in pregnancy or reported pregnancy or money problems had significantly higher reading scores. When measured as a weighted scale, antenatal stress exposure also showed a significant positive effect on reading in boys. Van den Bergh and co-authors reported that high antenatal maternal anxiety was associated with impulsivity during performance of cognitive tasks in 14-15 year old adolescents, with boys being more susceptible to this influence than girls [35]. However, our results cannot be directly compared with the Van den Bergh et al. study due to the differences in both the outcome variables (performance of cognitive tasks in the former versus numeracy and literacy scores in ours) and the measures of antenatal stress: subjective experiences of emotions/tension were measured in the previous study, but exposure to life stress events in pregnancy was collected in our investigation.

Our finding that boys demonstrated higher reading and writing scores if their mothers experienced moderate stressful events during pregnancy is interesting in the context of the non-human literature. A range of studies conducted in laboratory animals has shown that prenatal stressors can cause feminization of neurobiological structures, hormones and neurotransmitters in males, with corresponding effects on behaviour (see [38] for a review). In particular, while maternal stress increases corticosterone levels in both males and female foetuses, only in males does it decrease foetal testosterone and brain aromatase activity, and alters brain catecholamine activity to approach that of females. It is import to note, however, that in prenatally stressed females the size of the anterior commissure was reduced to that in control males. It is also useful to note that some animal 
studies have shown that mild gestational stress was linked to improved learning in male rats [39, 40]. In humans, it has been shown that fetal testosterone concentration in utero is inversely correlated with emerging language skills in toddlers [41]. Reading and writing are important measures of language skills which are area of cognitive strength of females [42]. The positive association between prenatal stress exposure and improved literacy skills in boys as found in our study might be underpinned by a process similar to the feminization of neurobiological structures found in male animals.

In human research, DiPietro et al. [43] reported a positive association between a low-moderate level of prenatal sub-clinical anxiety, stress and depression and advanced motor and mental development at age two. In another study, elevated levels of maternal cortisol late in gestation were associated with accelerated cognitive development over the first year and higher scores on the Bayley Scales of Infant Development at 12 months [3]. While DiPietro and co-authors tested for but did not find sex significant differences (possibly due to the small total sample size, $\mathrm{N}=95$ ) and Davis and Sandman did test for sex differences, their findings have shown that a positive effect of moderate prenatal stress on offsprings' cognitive outcomes is possible.

We have conducted two sets of three-group and 11 two-group null hypothesis tests and multiple testing could be an issue. However, our findings have clearly shown that the direction of associations between maternal LSEs in pregnancy and reading achievement is negative for girls but predominantly positive for boys. The magnitude of the association is substantial, where $p \leq 0.05$, for example, the decrease in reading score for girls is between 33 to 97 points, equivalent to one to four quarters of the standard deviation (104)), whereas in boys the increase is between 22 to 42 points or $1 / 5$ to $2 / 5$ of the standard deviation. Further, these sex differences remained unchanged when maternal LSEs in pregnancy was measured and analysed as a single weighted scale, where multiple testing is not an issue. Thus, it is unlikely that the sex differences we have found in this 
study are attributable to a chance effect. Our preliminary analyses based on pooled data showed no significant association between maternal exposure to LSEs and school achievement, because the effects in males and females 'averaged out' when both sexes were combined. Thus, our findings highlight the importance of examining possible sex differences and failure to do so would lead to erroneous conclusions.

\section{Strengths and Limitations}

Compared with the majority of previous studies, this study was based on a relatively large number of participants with longitudinal data obtained on exposures to LSEs in pregnancy and post natally. The study examined robust measures of literacy and numeracy as outcome variables, and we were able to adjust for a range of potential confounders. We examined different aspects rather than only one dimension of maternal LSEs in pregnancy and identified significant sex differences in the effect of maternal exposure to LSEs on reading achievement in children, with important implications for future research. One limitation of this study is the lack of biological measures of maternal stress hormone levels during the times of LSE exposure. We were unable to determine the extent to which self-reported LSEs were correlated with cortisol measures in the mother's blood and/or saliva, therefore the biological pathways linking maternal antenatal stress exposure to child developmental outcomes are only hypothetical in our study.

\section{Conclusions}

Antenatal stressors have a negative effect on grade five girls' reading scores, but it appeared to benefit scholastic achievement in grade five boys. Specifically, exposure to multiple stressful life events in pregnancy was negatively associated with reading scores in girls. The death of a relative and/or death of friend in pregnancy was particularly detrimental to the reading achievement of female offspring. Based on these findings, social support for mothers exposed to such life events in pregnancy may be recommended as an integral part of antenatal and postnatal care for the mother and child. In contrast, boys whose mothers had multiple stressful life events in pregnancy scored 
higher in the reading and writing tests. Thus, exposure to stressors in pregnancy does not have a universally negative impact on all individuals. Further research is needed to confirm our findings and explore biological and other pathways through which maternal exposure to LSEs in pregnancy influences male and female offspring differently.

Abbreviations: LSEs: Life Stress Events; KEMH: King Edward Memorial Hospital; WALNA: The Western Australian Literacy and Numeracy Assessment; WA: Western Australia; UWA: The University of Western Australia; NH\&MRC: National Health and Medical Research Council of Australia; CI: Confidence Interval; The Raine Study: The Western Australian Pregnancy Cohort Study. 


\section{References}

[1] Bergman K, Sarkar P, O’Connor TG, Modi N, Glover V. Maternal stress during pregnancy predicts cognitive ability and fearfulness in infancy. Journal of the American Academy of Child and Adolescent Psychiatry 2007;46:1454-63.

[2] Buitelaar JK, Huizink AC, Mulder EJ, de Medina PGR, Visser GHA. Prenatal stress and cognitive development and temperament in infants. Neurobiology of Aging. 2003;24:S53-S60.

[3] Davis EP, Sandman CA. The timing of prenatal exposure to maternal cortisol and psychosocial stress is associated with human infant cognitive development. Child Development. 2010;81:131-48. [4] van den Bergh BRH, Mennes M, Oosterlaan J, Stevens V, Stiers P, Marcoen A, et al. High antenatal maternal anxiety is related to impulsivity during performance on cognitive tasks in 14and 15-year-olds. Neuroscience \& Biobehavioral Reviews. 2005;29:259-69.

[5] Beydoun H, Saftlas AF. Physical and mental health outcomes of prenatal maternal stress in human and animal studies: a review of recent evidence. Paediatric \& Perinatal Epidemiology. 2008;22:438-66.

[6] Lazinski M, Shea A, Steiner M. Effects of maternal prenatal stress on offspring development: A commentary. Archives of Women's Mental Health. 2008;11:363-75.

[7] Talge NM, Neal C, Glover V, the Early Stress TRaPSNFaNEoCaAMH. Antenatal maternal stress and long-term effects on child neurodevelopment: how and why? Journal of Child Psychology and Psychiatry. 2007;48:245-61.

[8] Ramchandani PG, Richter LM, Norris SA, Stein A. Maternal prenatal stress and later child behavioral problems in an urban south African setting. Journal of the American Academy of Child \& Adolescent Psychiatry. 2010;49:239-47.

[9] Robinson M, Mattes E, Oddy WH, Pennell CE, van Eekelen JAM, McLean NJ, et al. Prenatal stress and risk of behavioural morbidity from age two to 14 years: The influence of the number, type and timing of stressful life events. Development and Psychopathology. 2011;23:507-20. 
[10] O’Connor TG, Heron J, Glover VPD. Antenatal anxiety predicts child behavioral/emotional problems independently of postnatal depression. Journal of the American Academy of Child \& Adolescent Psychiatry. 2002;41:1470-7.

[11] Huizink AC, Robles de Medina PG, Mulder EJ, Visser GH, Buitelaar JK. Stress during pregnancy is associated with developmental outcome in infancy. Journal of Child Psychology and Psychiatry. 2003;44:810-8.

[12] LaPlante D, Brunet A, Schmitz N, Clampi A, King S. Project Ice Storm: Prenatal maternal stress affects cognitive and linguistic functioning in 51/2-year-old children. Journal of American Academy of Child and Adolescent Psychiatry. 2008;47:1063-72.

[13] Crone EA. Executive functions in adolescence: inferences from brain and behavior.

Developmental Science 2009;12:825-30.

[14] Pous T. Mapping brain maturation and cognitive development during adolescence. Trends in Cognitive Sciences. 2005;9 60-8.

[15] Mennes M, van den Bergh BRH, Lagae L, Stiers P. Developmental brain alterations in 17 year old boys are related to antenatal maternal anxiety. Clinical Neurophysiology. 2009;120:1116-22. [16] Mennes M, Stiers P, Lagae L, van den Bergh BRH. Long-term cognitive sequelae of antenatal maternal anxiety: involvement of the orbitofrontal cortex. Neuroscience \& Biobehavioral Reviews. 2006;30:1078-86.

[17] Coltheart M, Prior M. Learning to Read in Australia. The Academy of Social Sciences in Australia. 2007; Occasional Paper 1/2007, Policy Paper No. 6.

[18] Beswick JF, Sloat EA. Early Literacy Success: A matter of social justice. Education Canada. 2006;46:23-6.

[19] Blau PM, Duncan OD. The American Occupational Structure. New York: Wiley; 1967.

[20] Niederhofer H, Reiter A. Prenatal maternal stress, prenatal fetal movements and perinatal temperament factors influence behaviour and school marks at the age of 6 years. Fetal Diagnosis and Therapy. 2004;19:160-2. 
[21] Niederhofer H, Reiter A. Prenatal maternal stress, prenatal fetal movements and perinatal temperament factors influence behavior and school marks at the age of 6 years. Fetal Diagn Ther. 2004;19:160-2.

[22] Zagron G, Weinstock M. Maternal adrenal hormone secretion mediates behavioural alterations induced by prenatal stress in male and female rats. Behav Brain Res. 2006;175:323-8.

[23] Clifton VL, Murphy VE. Maternal asthma as a model for examining fetal sex-specific effects on maternal physiology and placental mechanisms that regulate human fetal growth. Placenta. 2004;25 Suppl A:S45-52.

[24] Kronenberg ME, Hansel TC, Brennan AM, Osofsky HJ, Osofsky JD, Lawrason B. Children of Katrina: Lessons learned about postdisaster symptoms and recovery patterns. Child Development. 2010;81:1241-59.

[25] Vigil JM, Geary DC, Granger DA, Flinn MV. Sex differences in salivary cortisol, alphaamylase, and psychological functioning following hurricane Katrina. Child Development. 2010;81:1228-40.

[26] DeRijk RH, De Kloet ER. Corticosteroid receptor polymorphisms: Determinants of vulnerability and resilience. European Journal of Pharmacology 2008;583:303-11.

[27] Ellis BJ, Jackson JJ, Boyce WT. The stress response systems: Universality and adaptive individual differences. Developmental Review. 2006;26:175-212.

[28] Newnham JP, Evans SF, Michael CA, Stanley FJ, Landau LI. Effects of frequent ultrasound during pregnancy: A randomised controlled trial. The Lancet. 1993;342:887.

[29] Kelman C, Bass A, Holman C. Research use of linked health data - a best practice protocol. Australian and New Zealand Journal of Public Health. 2002;26:251-5.

[30] Rasch G. Probabilistic models for some intelligence and attainment tests. Chicago: The University of Chicago Press; 1980. 
[31] Carmichael SL, Shaw GM, Yang W, Abrams B, Lammer EJ. Maternal stressful life events and risks of birth defects. Epidemiology. 2007;18:356-61.

[32] Miller MA, Rahe RH. Life changes scaling for the 1990s. J Psychosom Res. 1997;43:279-92.

[33] Li J, Kendall G, Henderson S, Downie J, Landsborough L, Oddy W. Maternal psychosocial well-being in pregnancy and breastfeeding duration. Acta Pædiatrica. 2008;97:221-5.

[34] Chugani HT. A critical period of brain development: studies of cerebral glucose utilization with PET. Preventive Medicine. 1998;27:184-8.

[35] van den Bergh BRH, Mulder EJH, Mennes M, Glover V. Antenatal maternal anxiety and stress and the neurobehavioural development of the fetus and child: links and possible mechanisms. A review. Neuroscience \& Biobehavioral Reviews. 2005;29:237-58.

[36] Seckl JR, Holmes MC. Mechanisms of disease: glucocorticoids, their placental metabolism and fetal 'programming' of adult pathophysiology. Nature Clinical Practice Endocrinology and Metabolism. 2007;3:479-88.

[37] Entringer S, Buss C, Kumsta R, Hellhammer DH, Wadhwa PD, Wüst S. Prenatal psychosocial stress exposure is associated with subsequent working memory performance in young women. Behavioral Neuroscience. 2009;123:886-93.

[38] Weinstock M. The potential influence of maternal stress hormones on development and mental health of the offspring. Brain, Behavior and Immunity. 2005;19:296-308.

[39] Cannizzaro C, Plescia F, Martire M, Gagliano M, Cannizzaro G, Mantia G, et al. Single, intense prenatal stress decreases emotionality and enhances learning performance in the adolescent rat offspring: interaction with a brief, daily maternal separation. Behav Brain Res. 2006;169:128-36. [40] Fujioka T, Fujioka A, Tan N, Chowdhury GM, Mouri H, Sakata Y, et al. Mild prenatal stress enhances learning performance in the non-adopted rat offspring. Neuroscience. 2001;103:301-7. [41] Lutchmaya S, Baron-Cohen S, Raggatt P. Foetal testosterone and vocabulary size in 18-and 24-month-old infants. Infant Behavior \& Development. 2002;24:418-24. 
[42] Whitehouse AJO. Is There a Sex Ratio Difference in the Familial Aggregation of Specific Language Impairment? A Meta-Analysis. Journal of Speech Language and Hearing Research. 2010;53:1015-25.

[43] DiPietro JA, Novak MFSX, Costigan KA, Atella LD, Reusing SP. Maternal psychological distress during pregnancy in relation to child development at age two. Child Development. 2006;77:573-87.

\section{Figure Legend}

Figure1. Maternal exposure to stressful life events in pregnancy and reading score at age 10 


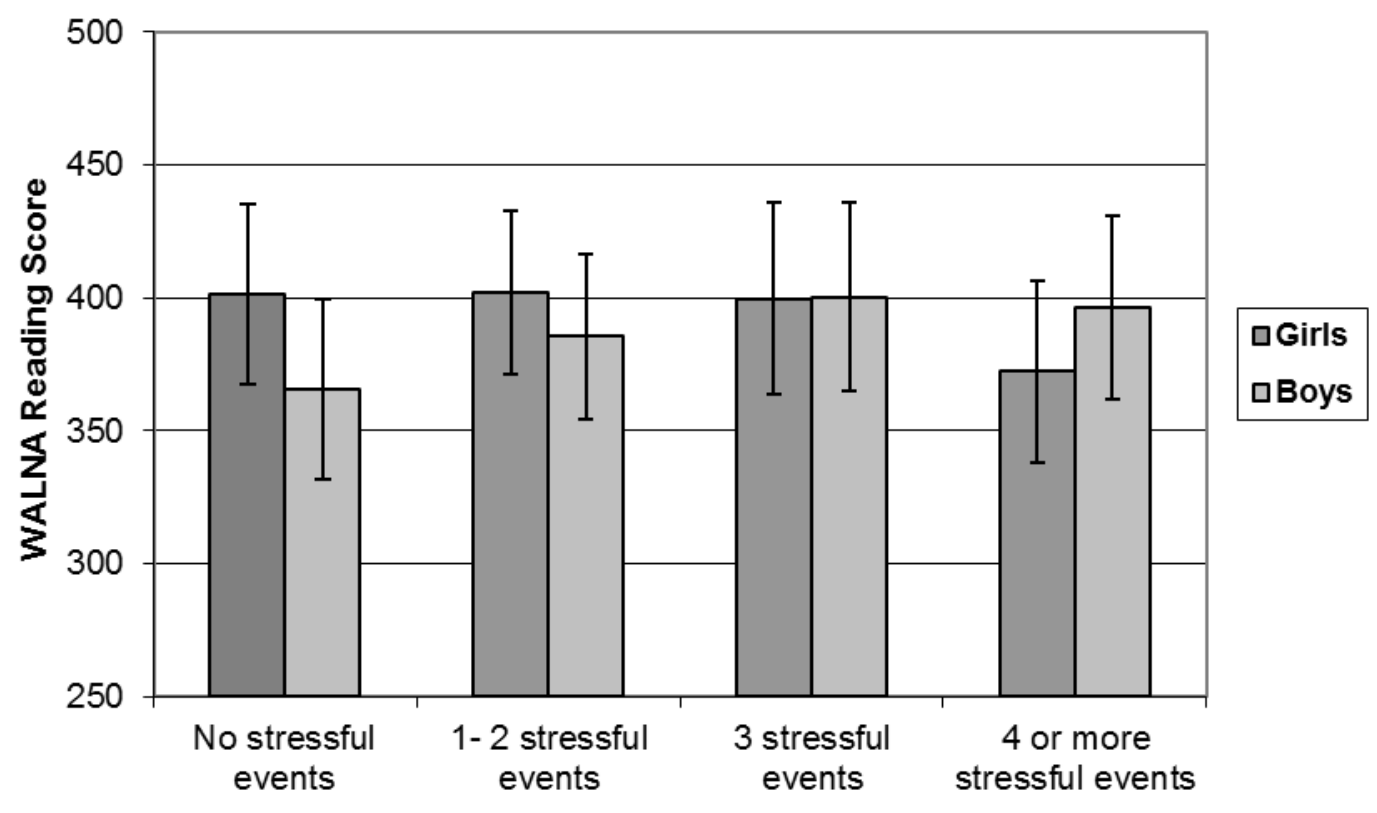

Figure Legend

Figure1. Maternal exposure to stressful life events in pregnancy and reading score at age 10 
Table 1 Average numeracy and literacy scores at age 10 by gender

\begin{tabular}{|l|l|l|l|l|l|l|l|l|l|l|}
\hline & \multicolumn{2}{|c|}{$\begin{array}{c}\text { All } \\
(\mathrm{n}=1038)\end{array}$} & \multicolumn{2}{c|}{$\begin{array}{c}\text { Boys } \\
(\mathrm{n}=521)\end{array}$} & \multicolumn{2}{c|}{$\begin{array}{c}\text { Girls } \\
(\mathrm{n}=516)\end{array}$} & $\begin{array}{c}\text { Difference } \\
\text { in mean }\end{array}$ & $\begin{array}{c}\text { P- } \\
\text { value }\end{array}$ & \multicolumn{2}{c|}{$\begin{array}{c}95 \text { Confidence } \\
\text { Interval }\end{array}$} \\
\hline & Mean & STD & Mean & STD & Mean & STD & & & Lower & Upper \\
\hline Maths & 397 & 106 & 403 & 111 & 391 & 101 & 12 & 0.069 & -24.87 & 91.49 \\
\hline Reading & 384 & 104 & 378 & 104 & 391 & 104 & -13 & 0.049 & 0.064 & 25.38 \\
\hline Spelling & 361 & 119 & 348 & 146 & 375 & 190 & -27 & 0.011 & 6.22 & 47.38 \\
\hline Writing & 423 & 169 & 409 & 116 & 437 & 121 & -28 & $<0.001$ & 13.98 & 42.91 \\
\hline
\end{tabular}


Table 2 Maternal experience of life stress events in pregnancy

\begin{tabular}{|c|c|c|c|c|c|c|c|c|c|c|c|c|}
\hline & \multicolumn{4}{|c|}{ All $(N=964)$} & \multicolumn{4}{|c|}{ Boys $(\mathrm{N}=486)$} & \multicolumn{4}{|c|}{ Girls (N=478) } \\
\hline & Mean & STD & Min & $\operatorname{Max}$ & Mean & STD & Min & Max & Mean & STD & Min & Max \\
\hline Total number of stressful events & 2.09 & 1.90 & 0 & 11 & 2.13 & 1.92 & 0 & 10 & 2.06 & 1.89 & 0 & 11 \\
\hline Weighted total stress events & 59.7 & 55.3 & 0 & 352 & 60.5 & 5.7 & 0 & 319 & 58.7 & 55.0 & 0 & 352 \\
\hline \multirow[t]{2}{*}{$\begin{array}{l}\text { Frequency of exposures to } \\
\text { stress events }\end{array}$} & \multirow{2}{*}{\multicolumn{2}{|c|}{ Frequency }} & \multirow{2}{*}{\multicolumn{2}{|c|}{ Percentage }} & \multirow{2}{*}{\multicolumn{2}{|c|}{ Frequency }} & \multirow{2}{*}{\multicolumn{2}{|c|}{ Percentage }} & \multirow{2}{*}{\multicolumn{2}{|c|}{ Frequency }} & \multirow{2}{*}{\multicolumn{2}{|c|}{ Percentage }} \\
\hline & & & & & & & & & & & & \\
\hline No stressful events & \multicolumn{2}{|l|}{206} & \multicolumn{2}{|l|}{21.4} & \multicolumn{2}{|l|}{101} & \multicolumn{2}{|l|}{20.8} & \multicolumn{2}{|l|}{105} & \multicolumn{2}{|l|}{22.0} \\
\hline 1 stressful event & \multicolumn{2}{|l|}{244} & \multicolumn{2}{|l|}{25.3} & \multicolumn{2}{|l|}{119} & \multicolumn{2}{|l|}{24.5} & \multicolumn{2}{|l|}{125} & \multicolumn{2}{|l|}{26.2} \\
\hline 2 stressful events & \multicolumn{2}{|l|}{178} & \multicolumn{2}{|l|}{18.5} & \multicolumn{2}{|l|}{96} & \multicolumn{2}{|l|}{19.8} & \multicolumn{2}{|l|}{82} & \multicolumn{2}{|l|}{17.2} \\
\hline 3 stressful events & \multicolumn{2}{|l|}{146} & \multicolumn{2}{|l|}{15.1} & \multicolumn{2}{|l|}{76} & \multicolumn{2}{|l|}{15.6} & \multicolumn{2}{|l|}{70} & \multicolumn{2}{|l|}{14.6} \\
\hline 4 or more stressful events & 190 & & 19.7 & & 94 & & 19.3 & & 96 & & 20.1 & \\
\hline Timing of exposure & & & & & & & & & & & & \\
\hline No stressful events & 206 & & 21.4 & & 101 & & 20.8 & & 105 & & 22.0 & \\
\hline Stress events at $18 \mathrm{wks}$ & 215 & & 22.3 & & 103 & & 21.2 & & 112 & & 23.4 & \\
\hline Stress events at $34 \mathrm{wks}$ & 131 & & 13.6 & & 66 & & 13.6 & & 65 & & 13.6 & \\
\hline Stress events at $18+34$ wks & 412 & & 42.7 & & 216 & & 44.4 & & 196 & & 41.0 & \\
\hline $\begin{array}{l}\text { Specific life stress events } \\
18+34 \text { wks }\end{array}$ & & & & & & & & & & & & \\
\hline
\end{tabular}




\begin{tabular}{|c|c|c|c|c|c|c|}
\hline Death of a friend & 33 & 3.4 & 14 & 2.7 & 19 & 3.6 \\
\hline Death of a relative & 86 & 8.9 & 38 & 7.4 & 48 & 9.2 \\
\hline Pregnancy problems & 361 & 37.4 & 188 & 36.4 & 173 & 33.2 \\
\hline Your own job loss & 34 & 3.5 & 18 & 3.5 & 16 & 3.1 \\
\hline Your partner's job loss & 78 & 8.1 & 37 & 7.2 & 41 & 7.9 \\
\hline Separation or divorce & 43 & 4.5 & 25 & 4.8 & 18 & 3.5 \\
\hline Marital problem & 115 & 11.9 & 55 & 10.7 & 60 & 11.5 \\
\hline Residential move & 245 & 25.4 & 116 & 22.5 & 129 & 24.8 \\
\hline Money problem & 342 & 35.5 & 177 & 34.3 & 165 & 31.7 \\
\hline Problem with your children & 102 & 10.6 & 48 & 9.3 & 54 & 10.4 \\
\hline Other problems & 204 & 21.2 & 96 & 18.6 & 108 & 20.7 \\
\hline
\end{tabular}


Table 3 Effects of maternal experience of stressful events in pregnancy on WALNA reading test scores at age 10

\begin{tabular}{|c|c|c|c|c|c|c|c|c|}
\hline & \multicolumn{4}{|c|}{ Girls } & \multicolumn{4}{|c|}{ Boys } \\
\hline & \multirow[b]{2}{*}{ Beta } & \multirow[b]{2}{*}{$P$-value } & \multicolumn{2}{|c|}{$95 \% \mathrm{Cl}$} & \multirow[b]{2}{*}{ Beta } & \multirow[b]{2}{*}{ P-value } & \multicolumn{2}{|c|}{$95 \% \mathrm{Cl}$} \\
\hline & & & $\begin{array}{l}\text { Lower } \\
\text { Bound }\end{array}$ & Upper Bound & & & Lower Bound & Upper Bound \\
\hline $\begin{array}{l}\text { Weighted scale of total stress } \\
\text { exposure }\end{array}$ & -0.18 & 0.04 & -0.35 & 0.01 & 0.17 & 0.05 & -0.002 & 0.34 \\
\hline $\begin{array}{l}\text { Weighted scale of total stress } \\
\text { exposure adjusting for stress } \\
\text { exposure at age one }\end{array}$ & -0.17 & 0.07 & -0.35 & 0.01 & 0.21 & 0.02 & 0.04 & 0.39 \\
\hline \multicolumn{9}{|l|}{$\begin{array}{l}\text { Frequency of exposure to } \\
\text { stress events }{ }^{1}\end{array}$} \\
\hline No stress events (reference) & ----- & ----- & ----- & ----- & 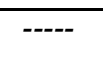 & ----- & ----- & ----- \\
\hline $1-2$ stressful events & -0.09 & 1.0 & -25.28 & 25.11 & 22.08 & 0.06 & -1.12 & 45.28 \\
\hline 3 stressful events & -4.73 & 0.78 & -34.47 & 28.02 & 41.23 & $<0.01$ & 11.37 & 71.09 \\
\hline 4 or more stressful events & -33.27 & 0.03 & -64.04 & -2.51 & 40.52 & $<0.01$ & 10.83 & 70.21 \\
\hline \multicolumn{9}{|l|}{ Timing of exposure $^{1}$} \\
\hline No stress events (reference) & ----- & $\begin{array}{c}---- \\
\end{array}$ & ----- & ----- & $\begin{array}{l}---- \\
\end{array}$ & ----- & $\begin{array}{c}---- \\
\end{array}$ & $\begin{array}{c}---- \\
\end{array}$ \\
\hline Stressful events 18 wks & -4.36 & 0.76 & -32.92 & 24.19 & 25.03 & 0.07 & -1.87 & 51.92 \\
\hline Stressful events 34 wks & 11.52 & 0.50 & -21.86 & 44.91 & 24.89 & 0.11 & -5.94 & 55.71 \\
\hline Stressful events $18+34$ wks & -18.38 & 0.17 & -44.56 & 7.80 & 32.72 & $<0.01$ & 8.30 & 57.18 \\
\hline Specific stress events $18+38$ & & & & & & & & \\
\hline
\end{tabular}




\begin{tabular}{|c|c|c|c|c|c|c|c|c|}
\hline wks $^{1,2}$ & & & & & & & & \\
\hline Death of a friend & -97.24 & $<0.001$ & -151.40 & -43.09 & -5.41 & 0.82 & -52.11 & 41.29 \\
\hline Death of a relative & -35.12 & 0.05 & -70.43 & 0.19 & 9.08 & 0.55 & -20.52 & 38.68 \\
\hline Pregnancy problems & -4.54 & 0.65 & -23.93 & 14.85 & 21.47 & 0.02 & 3.16 & 39.77 \\
\hline Your own job loss & 33.27 & 0.19 & -17.04 & 83.58 & 13.65 & 0.59 & -36.06 & 63.36 \\
\hline Your partner's job loss & -3.29 & 0.86 & -39.01 & 32.42 & 25.23 & 0.11 & -5.89 & 56.34 \\
\hline Separation or divorce & -38.51 & 0.12 & -86.61 & 9.59 & -14.10 & 0.60 & -37.16 & 65.34 \\
\hline Marital problem & -24.92 & 0.12 & -56.00 & -6.17 & 7.24 & 0.63 & -21.85 & 36.34 \\
\hline Residential move & 12.43 & 0.29 & -10.43 & 35.28 & -3.10 & 0.77 & -17.79 & 24.00 \\
\hline Money problem & -4.69 & 0.67 & -25.93 & 16.56 & 27.01 & 0.01 & 7.18 & 46.92 \\
\hline Problem with your children & -10.43 & 0.54 & -43.87 & 23.00 & 12.47 & 0.39 & -16.07 & 41.01 \\
\hline Other problems & -11.92 & 0.33 & -36.11 & 12.27 & 3.12 & 0.77 & -17.93 & 24.18 \\
\hline
\end{tabular}

${ }^{1}$ Each indicator of the stress event was analysed in a separate multivariate model that adjusted for maternal age, race, marital status, education, smoking in pregnancy, family income, and a weighted stress scale at both ages one and 10.

${ }^{2}$ The reference group was no exposure to a specific stressful event. 